\title{
Development of medical informatics in China over the past 30 years from a conference perspective and a Sino-American comparison
}

\author{
Jun Liang ${ }^{1}$, Kunyan Wei ${ }^{2}$, Qun Meng ${ }^{3}$, Zhenying Chen ${ }^{4}$, Jiajie Zhang ${ }^{5}$, Jianbo Lei ${ }^{\text {Corresp. } 6,7}$ \\ ${ }^{1}$ IT Center, Second Affiliated Hospital, School of Medicine, Zhejiang University, Hangzhou, Zhejiang Province, China \\ 3 Center for Statistics and Information, National Health and Family Planning Commission of China, Beijing, China \\ 4 Library of Zhejiang University, Hangzhou, Zhejiang Province, China \\ 5 School of Biomedical Informatics, University of Texas Health Sciences Center, Houston, Texas, United States \\ 6 Center for Medical Informatics, Peking University, Beijing, China \\ 7 School of Medical Informatics and Engineering, Southwest Medical University, Luzhou, Sichuan Province, China \\ Corresponding Author: Jianbo Lei \\ Email address: jblei@hsc.pku.edu.cn
}

Background: As the world's second-largest economy, China has launched health reforms for the second time and invested significant funding in medical informatics (MI) since 2010; however, few studies have been conducted on the outcomes of this ambitious cause.

Objective: This study analyzed the features of major MI meetings held in China and compared them with similar MI conferences in the United States, aiming at informing researchers on the outcomes of $\mathrm{MI}$ in China and the U.S. from the professional conference perspective and encouraging greater international cooperation for the advancement of the field of medical informatics in China and, ultimately, the promotion of China's health reform.

Methods: Qualitative and quantitative analyses of four MI meetings in China (i.e., CMIAAS, CHINC, CHITEC, and CPMI) and two in the U.S. (i.e., AMIA and HIMSS) were conducted. Furthermore, the size, constituent parts and regional allocation of participants, topics, and fields of research for each meeting were determined and compared.

Results: From 1985 to 2016, approximately 45,000 individuals attended the CMIAAS and CPMI (academic), CHINC and CHITEC (industry), resulting in 5,085 documented articles. In contrast, in 2015, 38,000 and 3,700 individuals, respectively, attended the American HIMSS (industry) and AMIA (academic) conferences and published 1,926 papers in the latter. Compared to those of HIMSS in 2015, the meeting duration of Chinese industry CHITEC was 3 vs. 5 days, number of vendors was 100 vs. 1500+, number of sub-forums was 10 vs. 250; While compared to those of AMIA, the meeting duration of Chinese CMIAAS was 2 vs. 8 days, number of vendors was 5 vs. 65+, number of sub-forums was 4 vs. 26. HIMSS and AMIA were more open, international, and comprehensive in comparison to the aforementioned Chinese conferences.

Conclusions: The current MI in China can be characterized as "hot in industry application, and cold in academic research." Taking into consideration the economic scale together with the huge investment in MI, conference yield and attendee diversity are still low in China. This study demonstrates an urgent 
necessity to elevate the medical informatics discipline in China and to expand research fields in order to maintain pace with the development of medical informatics in the U.S. and other countries. 
1 Development of medical informatics in China

2 over the past $\mathbf{3 0}$ years from a conference

3 perspective and a Sino-American comparison

4

5 Jun Liang, M.S. ${ }^{1}$, Kunyan Wei, MD. ${ }^{2}$, Qun Meng, Ph.D. ${ }^{3}$, Zhenying Chen, M.S. ${ }^{4}$, Jiajie Zhang,

6 Ph.D. ${ }^{5}$, Jianbo Lei M.D., Ph.D. $67^{*}$

7

$8{ }^{1}$ IT Center, Second Affiliated Hospital, School of Medicine, Zhejiang University, Hangzhou,

9 Zhejiang Province, China

10 2Department of Gastroenterology, Affiliated Hospital of Southwest Medical University, Luzhou,

11 Sichuan Province, China

$12{ }^{3}$ Center for Statistics and Information, National Health and Family Planning Commission of

13 China, Beijing, China

$14{ }^{4}$ Library of Zhejiang University, Hangzhou, Zhejiang Province, China

$15{ }^{5}$ School of Biomedical Informatics, University of Texas Health Sciences Center, Houston, TX,

16 USA

$17{ }^{6}$ Center for Medical Informatics, Peking University, Beijing, China

$18{ }^{7}$ School of Medical Informatics and Engineering, Southwest Medical University, Luzhou,

19 Sichuan Province, China 


\section{Corresponding Author:}

23 Jianbo Lei, M.D., Ph.D. Associate Professor

24 Center for Medical Informatics, Peking University, 38 Xueyuan Rd, Haidian District, Beijing

25 100191, China

26 Tel: +86 (10) 8280-5901

27 Fax: +86 (10) 8280-5900

28 Email: jblei@hsc.pku.edu.cn 


\section{ABSTRACT}

30 Background: As the world's second-largest economy, China has launched health reforms for the

31 second time and invested significant funding in medical informatics (MI) since 2010; however,

32 few studies have been conducted on the outcomes of this ambitious cause.

33 Objective: This study analyzed the features of major MI meetings held in China and compared

34 them with similar MI conferences in the United States, aiming at informing researchers on the

35 outcomes of MI in China and the U.S. from the professional conference perspective and 36 encouraging greater international cooperation for the advancement of the field of medical 37 informatics in China and, ultimately, the promotion of China's health reform.

38 Methods: Qualitative and quantitative analyses of four MI meetings in China (i.e., CMIAAS, 39 CHINC, CHITEC, and CPMI) and two in the U.S. (i.e., AMIA and HIMSS) were conducted. 40 Furthermore, the size, constituent parts and regional allocation of participants, topics, and fields 41 of research for each meeting were determined and compared.

42 Results: From 1985 to 2016, approximately 45,000 individuals attended the CMIAAS and CPMI 43 (academic), CHINC and CHITEC (industry), resulting in 5,085 documented articles. In contrast, 44 in 2015, 38,000 and 3,700 individuals, respectively, attended the American HIMSS (industry) 45 and AMIA (academic) conferences and published 1,926 papers in the latter. Compared to those 46 of HIMSS in 2015, the meeting duration of Chinese industry CHITEC was 3 vs. 5 days, number 47 of vendors was 100 vs. $1500+$, number of sub-forums was 10 vs. 250 ; While compared to those 48 of AMIA, the meeting duration of Chinese CMIAAS was 2 vs. 8 days, number of vendors was 5 49 vs. $65+$, number of sub-forums was 4 vs. 26. HIMSS and AMIA were more open, international, 50 and comprehensive in comparison to the aforementioned Chinese conferences. 
51 Conclusions: The current MI in China can be characterized as "hot in industry application, and 52 cold in academic research." Taking into consideration the economic scale together with the huge 53 investment in MI, conference yield and attendee diversity are still low in China. This study 54 demonstrates an urgent necessity to elevate the medical informatics discipline in China and to 55 expand research fields in order to maintain pace with the development of medical informatics in 56 the U.S. and other countries.

57 


\section{INTRODUCTION}

\section{Development of the Discipline of Medical Informatics}

61 Medical informatics (MI) is a multidisciplinary field in which researchers pursue scientific 62 exploration, problem-solving, and decision-making to facilitate the effective use of biomedical 63 data, information, and knowledge for the improvement of human health (Kulikowski et al. 2012). 64 First proposed in 1970 (Haux 2010), medical informatics currently includes 20 subfields, such as 65 clinical informatics (Kulikowski 2007; M.J.Sehuemie et al. 2009); over time, the focus of MI 66 research has shifted from hardware and software innovation to software systems and 67 information-processing models, particularly data and knowledge description and management, 68 computerization, and evaluation (Kulikowski 2007). Medical informatics has been recognized 69 worldwide as an emerging, independent, and important interdisciplinary field.

\section{High-level Design and Industry Development of Hospital Informatics in China}

72 Rapid economic development and recent health care reforms in China have greatly facilitated the

73 development of hospital informatics. In 2010, as China became the world's second-largest 74 economy, the Chinese government initiated its second health care reform, which is the largest 75 since the founding of the P. R. China, with an announcement that "medical information systems 76 and population health informatics" would be one of the "four pillars, eight posts" supporting 77 reforms in the health care field (Qun 2011). Guided and stimulated by these policies, the Chinese government and healthcare informatics users have made substantial investments in population

79 health informatics and hospital informatics. During the past and $12^{\text {th }} 5$-year plan, encompassing 80 the period between 2011 and 2015, the Chinese government began investing a considerable

81 amount of money for the purpose of promoting the construction of health information. The 
82 central government alone directly appropriated 1.5 billion US dollars for village-level and 83 county-level information construction projects in the Midwest region's 22 provinces. The former

84 included health information system construction for primary health care institutions covering all

85 the public Township and community health institutions; in addition, the central government 86 invested 45 million US dollars for the health information projects of 16 health care reform pilot 87 cities, 120 million US dollars for 16 provincial information platform construction projects, and 8860 million US dollars for telemedicine information system projects covering 22 provinces. By 89 2020, the government will further invest more than 3 billion US dollars for the "national 90 electronic health information systems engineering" project(Hu J et al. 2016). In 2015, the market 91 of hospital informatics alone reached 5 billion US dollars; by 2020, this market is projected to 92 exceed 14.5 billion US dollars, at an annual compound growth rate of $\geq 24 \%$ (Luo 2014).

93 Given the space limitations of this paper, readers may refer to Appendix A-1 (Evolution of 94 Hospital Informatics in China) if interested in additional information.

Development of the Medical Informatics Discipline in China is relatively behind that of the 97 U.S.

In China, the discipline of medical informatics is primarily characterized by a mismatch between the developmental model and hospital informatics. Medical informatics had a late start, with roots in traditional medical information and library science. Originating in China during the 1970s, this discipline has been evolving for over three decades (LI \& LIU 2014). Because various biomedical and computer technologies are widely used in the medical field in China, the research focus of medical informatics has expanded from library informatics and information 104 technology at information organizations, to information theory research, business systems, and 
105 the construction and application of infrastructure in the medical field. At present, medical 106 informatics research in China focuses on Health Information Technology (HIT)-related 107 organizations and includes HIT application and evaluation (e.g., hospital information systems); 108 medical information research and services; and medical information resource development, 109 retrieval, and services. Hospital information systems are primarily implemented and applied by 110 each hospital; medical information research and services are the major obligation of medical 111 information research institutes; and medical information resources development, retrieval, and 112 services are the major obligation of medical libraries.

113 An evolving interdisciplinary subject in China, medical informatics (MI) remains relatively

114 backward; until recently, the concept was not clearly defined or widely accepted (Lei et al. 2016).

115 As with any discipline, MI requires systematic support-inclusive of related mainstream journals, 116 publications, agencies, associations, and academic institutions - in order to become established 117 and advance (Dong 2004). However, as mentioned previously, medical informatics in China is 118 subject to the influence of traditional medical information and library science, as well as

119 historical and other challenges. Nevertheless, with rapid economic growth, the importance that 120 the government ostensibly places on the development of medical informatics - in the form of 121 government-led top design and huge investments - and China's myriad medical institutions and 122 its massive population, there is now an unprecedented opportunity for medical informatics to 123 successfully evolve. To this end, it will be important to strengthen international cooperation so 124 that China and other countries may learn from one another and promote the development of 125 medical informatics.

126 This paper focuses on four national mainstream medical informatics conferences and 127 compares their data with the data from two international medical informatics conferences based 
128 in the U.S. (i.e., the AMIA ${ }^{1}$ and HIMSS meetings). This aims to explore the differences and

129 identify the lessons learned in order to aid Chinese researchers and their international colleagues

130 in understanding the characteristics of medical informatics in China and how progress might be

131 made. Here, the overall goal is sharing China's experience with other countries, for the purpose

132 of promoting the exchange of knowledge worldwide for the improvement of China's medical

133 informatics as well as that of other nations, if possible, that are likely to lag in the discipline.

134

135

136

137

138

139

140

141

142

143

144

145

146

147

148

149

\section{BACKGROUND}

\section{Mainstream Chinese Medical Informatics Conferences and Their Evolution}

There are four mainstream Chinese medical informatics conferences: the China Hospital Information Network Conference (CHINC), the Chinese Medicine Information Association Annual Symposium (CMIAAS), the China Proceedings of Medical Informatics (CPMI) and the China Health Information Technology Exchange Conference (CHITEC). Basic information on these four conferences is presented in Table 1 below.

[Table 1 insert here]

Please refer to Appendix A-2 (Evolution of Chinese Mainstream Medical Informatics Conferences) for more information regarding these conferences, including descriptions of these conferences, related organizations and their URLs.

\section{MATERIALS AND METHODS}

${ }^{1}$ Including annual symposium and joint summits, for the sake of convenience, together as AMIA. 


\section{Selection of Mainstream MI conference in China}

151 According to the PRISMA (Preferred Reporting Items for Systematic Reviews and Meta-

152 Analysis) method (Moher et al. 2009), the selection criteria are defined as follows:

153 1. The academic topics of the meeting must be related to medical informatics, including but 154 not limited to: clinical informatics, bioinformatics, drug informatics, nursing informatics, public 155 health informatics, medical image informatics, etc.;

156 2. The meeting must be organized by a national academic organization or international 157 academic organization in China;

158 3. The meeting must call for papers through academic journals or an international open 159 approach;

160 4. The meeting must be continuous and have been held at least 5 times.

161 5. The meeting must have a certain degree of visibility, academic credibility and influence 162 in China's medical informatics community.

163 Ultimately, we chose 4 HIT meetings as the major meetings in mainland China, namely: 164 CMIAAS hosted by CMIA (the only country representative of IMIA), CPMI hosted by CSMI, 165 CHINC hosted by CHIMA and CHITEC hosted by CHIA.

166

\section{Collection of Data}

168 China's top three biggest literature databases were searched: the VIP database of Chinese 169 scientific and technical journals, the Chinese National Knowledge Infrastructure, and the

170 Wanfang data retrieval platform. These databases were searched for "会议论文集 (meeting 171 proceedings)." Keywords included the Chinese name of the conference (中国医药信息学大会 172 [CMIAAS], 中华医院网络信息大会 [CHINC], 中国卫生信息技术交流大会 [CHITEC], 
173 and 中华医学会全国医学信息学术会议 [CPMI]), the Chinese organizer of the conference (中

174 国医药信息学会 [China Medical Informatics Association] [CMIA], 中国医院协会信息管理

175 专业委员会 [the Committee on Information Management, Chinese Hospital Association]

176 [CHIMA], 中国卫生信息学会 [China Institutes of Health Information] [CHIA], and 中华医学

177 会医学信息分会 [the Medical Informatics Branch, Chinese Medical Society] also known as

178 [Chinese Society of Medical Information] [SCMI]), as well as the English acronym of each

179 meeting (CMIAAS, CHITEC, CHINC, and CPMI). Meeting proceedings between 1985 and

1802015 were retrieved. Furthermore, related supporting information, together with biographical

181 references, was also searched, such as the purpose, business scope, and "call for papers" about 182 each meeting.

183 Data about the Healthcare Information and Management Systems Society (HIMSS) and the 184 American Medical Informatics Association (AMIA), which are the two major U.S. medical 185 informatics meetings, were obtained from literature reviews (Fickenscher 2013a; Fickenscher 186 2012a; Fickenscher 2012b; Fickenscher 2013b; Fickenscher 2013c; Fickenscher 2013d; 187 Middleton 2014; Ravvaz et al. 2015; Shortliffe 2011a; Shortliffe 2011b) as well as the "letter of 188 welcome" for AMIA and HIMSS and websites about meeting organizers.

\section{Extraction of Data}

191 Information about target meetings from the literature and databases was exported, for instance:

192 1. Meeting size, including the meeting's name, who held it and when it was held, its 193 schedule, the duration, the number of participants, etc.

194 2. General information regarding the proceedings, for instance, title, author affiliation, 195 publication year, meeting name, and where the author lives (a self-developed tool is extracted). 
197 for papers" of the CMIAAS, CPMI, CHINC, and CHITEC (2000-2015) and the organizer's

198 business scope. According to the results, these meetings mainly dealt with highly similar topics 199 in 10 fields of research, including but not limited to hospital informatics, regional as well as 200 grassroots health informatics and telemedicine.

201

202

\section{Data Analysis}

203 EndNote X7, EXCEL 2011, and Python were used for a preliminary analysis of the general 204 information assembled, along with proceedings topics. The results of the analysis were described 205 from the perspective of the actual developmental circumstances of medical informatics and HIT 206 in China.

207

208

209

\section{RESULTS}

\section{Overall Volume and Trend of Conference Proceedings}

211 We searched three mainstream Chinese databases and retrieved a total of 6,681 papers from the 212 proceedings of four conferences (1985 to 2015). For the purposes of this study, we intentionally 213 selected conference proceedings published after 2008 because most conference papers $(76 \%$,

2145085 papers) were published on or after 2008, when publication and database entries for medical 215 informatics conference proceedings became more standardized and comprehensive in China. 216 This choice contributed to the alignment and data analysis of the proceedings. Moreover, during 217 that time, the Chinese government was preparing to propose its "second health care reform," and 218 HIT application was about to burst onto the scene. 
[Figure 1 insert here]

220

Figure 1 shows Chinese MI conference proceedings trends, by conference, from 2008-2015,

221 excluding some unavoidable gaps. It can be seen clearly that the growth rate of industry

222 conference submission is much higher than that of academic conferences, and CMIAAS even

223 had negative growth. The overall trend of papers published in various Chinese MI conferences

224 demonstrated a tendency of "hot in industry application, and cold in academic research". In

225 addition, We observed that the CPMI proceedings were incomplete (i.e., the CPMI-2013 was

226 missing) and, for CHINC and CHITEC, a large percentage of the proceedings were missing,

227 including the CHINC 2009-2011 and 2013, as well as CHITEC 2009, 2010, and 2012. We

228 conducted preliminary descriptive statistical data analysis for each conference, with a focus on

229 the continuity of proceedings entries in the literature databases. Note that, in PubMed, all AMIA

230 proceedings since 1977 (annual symposium) and 2008 (joint summits) are available for

231 download free-of-charge; in China, however, databases for the four mainstream medical

232 informatics conferences are neither continuous nor unified, and downloading is not

233 complimentary. Literature articles were distributed among three different databases, and some

234 proceedings were downloadable only from the conference's association website.

235 In addition, we examined conference and editorial reviews of the proceedings and observed

236 that, unlike international mainstream medical informatics conferences (e.g., AMIA), which

237 implement a rigorous review process for submitted manuscripts (Kulikowski 2007), Chinese

238 medical informatics conferences have yet to implement a process of peer-review for submitted

239 papers, in most cases, only style and formatting requirements checking had been done; For some

240 MI conferences in China, the acceptance rate was higher than 90\% (Li 2015; Ya-min et al. 2011;

241 Yajie et al. 2015; Yajie et al. 2014). The main reason for such few submission and high 
242 acceptance is likely due to a weak foundation for medical informatics and an insufficient pool of 243 qualified peer-reviewers.

244

245 Number of Attendees and Trends

246 To compare the number of submitted conference papers and align the data across different 247 conferences, we collected relevant information on all conference sessions from each conference 248 website, as well as corresponding association websites. Note that CHITEC'16, CHINC'16, and 249 CPMI'16 had finished, but the organizers have released on their homepages only attendance 250 information such as number of participants, while the proceedings are not available in these 251 databases. For CHITEC'16, CHINC'16, and CPMI'16, we have only the number of participants 252 in the comparisons. Figure 2 depicts the trend of conference attendees from 2008-2016, 253 excluding CMIAAS (2008-2015), showing that the number of attendees declined slightly at 254 CMIAAS and increased by only 140 from 2008-2016 at CPMI. By contrast, the number of 255 attendees increased dramatically at CHINC and CHITEC, by 3.9-fold and 8.3-fold, respectively, 256 over 2008-2016, which is consistent with results described in this section. It is within expectation 257 that the number of attendees was highly consistent with the trend of published proceedings, 258 further confirmed the characteristic of Chinese MI development, "hot in industry application, and 259 cold in academic research".

[Figure 2 insert here]

261

262

\section{Source of Conference Proceedings: Types of First-author Affiliations}

263 Author affiliations were selected according to the requirements delineated in each conference's 264 "call for papers," inclusive of medical institutions, universities, research institutions, and 
265 manufacturers. We referenced similar international evaluations and focused on first-author 266 affiliations, which proved to be a good indicator of each type of first-author affiliation. Figure 3

267 shows the type and percentage of first-author affiliations ( $\%$ all affiliations) among available 268 conference proceedings from 2008-2015.

269

[Figure 3 insert here]

270 Figure 3 shows a clear trend of author affiliations for four Chinese mainstream medical 271 informatics conferences:

272 1. Most attendees (indirectly inferred from the distribution of authors because of data 273 availability) of Chinese medical informatics conferences (CMIAAS, CHINC, CHITEC, and 274 CPMI) were from "medical institutions," which differed from the attendees of annual HIMSS 275 and AMIA conferences; most AMIA conferences attendees were from universities and research 276 institutes, and the largest HIMSS attendee group was software providers in the HIT industry. 277 Moreover, significantly more attendees were from "medical institutions" than from other 278 institutions, whereas $78.3 \%$ of attendees at the CHINC were from medical institutions, which 279 may reflect the purpose of the organizer, China Hospital Information Management Association 280 (CHIMA), which focuses on domestic and foreign hospital information management. At the 281 CMIAAS, 33.2\% of attendees were from universities, which is consistent with MEDINFO 282 attendees (Kulikowski 2014). CHITEC is a semi-official mainstream Chinese medical 283 informatics conference; thus, many attendees ( $>25 \%)$ were from "health administrative 284 authorities." At the CPMI, attendees were evenly distributed among the various entities; such 285 representation was most likely because the organizer SCMI was initially focused on traditional 286 medical information and library science and information services - therefore, attendees 287 represented universities, research institutes, or medical institutions. Unlike HIMSS, few 
288 attendees representing manufacturers submitted first-author papers to Chinese medical 289 informatics conferences. At CHINC, 13.9\% of attendees were manufacturers, whereas at the 290 other three conferences, the percentage was $\leq 7 \%$. Here, we use the distribution of the first 291 author of the conference paper to simulate the distribution of the actual participants, because the 292 accurate data of the actual participants can only be obtained from the various organizers and 293 cannot be obtained from the public channels.

294 2. The AMIA and HIMSS conferences represent two different medical informatics 295 exchange platforms: academic research (AMIA) and HIT application (HIMSS). Among 296 mainstream Chinese medical informatics conferences, CHINC and CHITEC are similar to 297 HIMSS and its focus on HIT applications. Most CHINC and CHITEC attendees were from 298 medical institutions or administrative authorities, and the scale of these conferences was also 299 large; in 2015, 667 papers were included in CHITEC proceedings and 853 in CHINC 300 proceedings. Similar to AMIA, the CMIAAS and CPMI are medical informatics conferences that 301 focus on academic exchange, as well as some HIT applications; most attendees were from 302 medical institutions, and some attendees were from universities and research institutes. Their 303 scale was much smaller; in 2015, only 70 papers were included in CMIAAS proceedings and 248 304 in CPMI proceedings. We compared the scale and attendee affiliations for these two types of 305 conferences and observed that, even at academic conferences, the percentage of attendees from 306 research institutes remained relatively low and that most papers focused on information systems 307 application in medical institutions. This information provided indirect evidence for the 308 postulation that "HIT is popular in industry application but unpopular in academic research in 309 medical informatics" (Lei et al. 2016). 


\section{Geographic Distribution of Conference Proceedings First Authors}

312 We also analyzed the geographic distribution (e.g., municipality, province, etc.) of practitioners 313 and researchers attending the previously described conferences from 2008-2015. Figure 4 shows 314 the distribution of first authors (percentage, by geographic area) for each of the conference 315 proceedings. The top three provinces and/or municipalities were selected, as shown below:

[Figure 4 insert here]

The academic disciplines and industry HIT development in different provinces and cities are unbalanced, showing the characteristics of "strong coastal areas in the East and weak inland areas in the West". This is because that comprehensive giant medical institutions, high-level medical information systems providers, research institutions are concentrated in a small number of eastern densely populated, medical and educational resources rich, economically developed municipalities and provinces.

We further compared and analyzed the statistics in Table 1 (above), and concluded the 324 following:

1. Not surprisingly, Chinese medical informatics conferences were more regional and local than those of AMIA and HIMSS; that is, most papers were submitted by first authors from a small number of provinces and municipalities; other papers were submitted by authors outside Mainland China (as noted by the designation "Others"). Among the top contributors (provinces and municipalities) to these four conferences, Beijing and Sichuan were in three of the "top three" lists, and Jiangsu was in two of the "top three" lists. Because Beijing is the capital of China (CHINA 2014a), this ranking was expected; Sichuan (Shi \& Zheng 2008) and Jiangsu (CHINA 2014b) are economically developed areas with abundant medical, scientific, and technological resources and an active and mature HIT market. In addition, unlike international 
334 mainstream medical informatics conferences (e.g., AMIA and HIMSS) (Maojo et al. 2012), few 335 practitioners or researchers outside Mainland China submitted papers to Chinese medical 336 informatics conferences. Because the international influence of China's medical informatization 337 is still very weak, the current positioning of these conferences is only as domestic conferences. 338 Everything from the conference themes and service targets to the contents of publications 339 reflects Chinese characteristics, and the conference exchange language is also Chinese.

340 2. Consistent with the economic development in different regions of China, the geographic 341 distribution of attendees was also highly uneven. For all four conferences, more than one-third of 342 attendees were from the top three provinces and/or municipalities $(\geq 50 \%$ at CMIAAS and 343 CHINC), indicating that, overall, less than half of the attendees were from the remaining 29 344 provinces, which is evidence of the uneven development of academic research and HIT 345 applications in medical informatics throughout various regions of China.

\section{Distribution of Conference Proceedings Topics}

348 We browsed titles and abstracts of conference proceedings and classified papers for topic areas 349 and statistically analyzed the results. We believe that the percentage of different topics covered 350 in conference proceedings provides indirect evidence of current hot and cold topics in Chinese 351 MI academic research and HIT application. The primary results (i.e., the distribution of topics for 352 CMIAAS, CHINC, CHITEC, and CPMI conference proceedings [2008-2015]) are shown in 353 Figure 5. 
355 Figure 5 shows the following characteristics related to the distribution of HIT applications 356 and research areas among the four Chinese mainstream medical informatics conference 357 proceedings:

358 1. "Health Information Technology (HIT) is popular in industry application but unpopular 359 in academic research for medical informatics." Specifically, more than $50 \%$ of topics for the four 360 conference proceedings were related to HIT applications in medical institutions and population 361 health informatics, such as "hospital informatics" and "public and regional, and grassroots health 362 informatics as well as telemedicine." These topics are consistent with the "four pillars, eight 363 posts" policies of current health care reform in China, which has driven substantial investments 364 in hospital and population health informatics.

365 2. Unlike topics in AMIA conference proceedings (Maojo et al. 2012), we observed few 366 topics (as low as $<1 \%$ ) in "medical informatics theory," "biomedical cognitive science," or 367 "standards, safety, legal, and related issues" in CHINC, CPMI, and CHINC conference 368 proceedings, and these topics were in AMIA's Call for Papers. Moreover, many areas in AMIA 369 and HIMSS conference proceedings, such as "dental informatics" and "consumer health 370 information," were not referenced in the "call for papers" of the four mainstream Chinese 371 medical informatics conferences. This dearth reflects the gap between the breadth and depth of 372 MI academic research as well as HIT applications in China and the U.S.

\section{DISCUSSION}


377 1. Weak foundation for MI. In China, the early-stage development of medical informatics

378 was dominated by library science and information, with no support from computer science and

379 information technology (Lei et al. 2016); thus, the state of the medical informatics discipline in

380 China is currently behind that of the U.S. and, potentially, other countries.

3812 . Missing subfields in the medical informatics discipline. Given the internationally 382 recognized categories of subfields in medical informatics, certain subfields remain missing or 383 under-developed in China.

384 3. The difficulty of using theories to solve practical issues. Few theoretical research studies 385 about medical informatics in China have been carried out, despite the numerous publications in 386 this field. Currently, graduate programs in medical informatics are available in only a few 387 Chinese teaching institutions.

388 4. Academic institutions in China cannot provide adequate numbers of sufficiently qualified 389 professionals to apply their knowledge of medical informatics in industry (e.g., hospital 390 information technology departments).

391 Due to the space limitations of this paper, readers may refer to Appendix A-3 (Unique 392 Characteristics of the Medical Informatics Discipline in China), if interested in further 393 information.

\section{MI Conferences in China and the U.S.: Further Analysis and Comparisons}

396 For more in-depth investigation of China's current research in medical informatics, the 397 application of HIT, meeting sessions, and the number of participants, subjects discussed at 398 meeting proceedings, academic research, and real-world applications as well as presentations of 399 academic achievements, participating vendors, and review criteria in China's four major medical 
400 informatics meetings (i.e., CMIAAS, CHINC, CHITEC, and CPMI, 2015), together with 401 preparation of AMIA (annual symposium and joint summits) and HIMSS (2015) are presented.

402 Figure 6 and 7 throw light on the results, and Table 2 brings forth the specific details.

403

404

405

406

407

408

409

410

411

412

413

414

415

416

417

418

419

420

421

422
[Figure 6 insert here]

[Figure 7 insert here]

[Table 2 insert here]

We analyzed the data in table and figures to reach the main conclusions regarding the status quo of the development of medical informatics in both China and America:

1. According to the cross-field research about the quantitative measures of Sino-U.S. academic and industrial exchange meetings, there is a huge gap between the two countries in terms not only of HIT applications but also of MI academic research.

1.1. In terms of academic exchange meetings, we compared the relatively large CPMI meeting (2015) with that of the AMIA (including the annual symposium as well as joint summits, 2015) and counted the number of participants as well as meeting papers of the CPMI, which were only approximately $8 \%$ of the total number of AMIA meeting papers. For the formats of demonstrating academic achievements, academic achievements were demonstrated at AMIA 2015 in a variety of ways, for instance, system demonstrations, fulltext papers, student papers, posters, abstracts, design contests, and descriptions; however, at CPMI 2015, academic achievements were demonstrated in merely two ways: full-text as well as exchange papers. Among these topics, discussions were carried out on merely 7 fields at CPMI 2015, and 70.6\% of papers were associated with information retrieval as well as hospital informatics; on the contrary, all of the 20 sub-fields associated with medical informatics were transferred at AMIA 2015. 
423

424

425

426

427

428

429

430

431

432

433

434

435

436

437

438

439

440 441 Computer Federation Academic Committee as "a significant internationally recognized 442

1.2. Regarding HIT application meetings, the gap was huge as well. Our comparison of the relatively large CHITEC 2015 as well as HIMSS 2015 showed that the number of participants at CHITEC 2015 was just $10 \%$ of that at HIMSS $2015(3,500+$ compared to $38,000+)$; the number of participating vendors at CHITEC 2015 was only approximately $8.3 \%$ of that at HIMSS $2015(100+$ compared to 1,200+). Academically, as respects valuerelated measures, CHITEC 2015 included merely 10 forums and 87 lectures on continued education, just $4 \%$ and $33 \%$, respectively, of the forums and lectures at HIMSS 2015 (250+ forums together with $300+$ continuing education lectures over 4 days). In terms of topics, 10 fields were transferred at CHITEC 2015, but 73.8\% of meeting papers were associated with population health informatics or hospital informatics; in contrast, all 20 sub-fields associated with medical informatics were discussed at HIMSS 2015.

2. A significant gap between the academic value of Chinese and American MI meeting proceedings papers was also noted. To be more specific, at Chinese HIT meetings, in most cases, only format review was carried out because of insufficient submitted papers and wellrounded peer reviewers who were trained in medical informatics courses. Therefore, the Chinese conference papers' academic value might be relatively low. In contrast, strict peer-review was carried out for AMIA 2015. According to the data available on the website, AMIA's proceedings papers' acceptance rate is lower than $30 \%$; consequently, AMIA is identified by the China meeting"(Committee 2015). In addition, in order to further determine the academic value of Sino-American medical information conferences, we take CPMI '15 and AMIA' 15 as an example, we use the Wanfang data retrieval platform and the PUBMED Central database to query paper citations. We found that the 248 CPMI ' 15 conference papers were cited 15 times, of 
446 which only 1 papers were cited 2 times, and 13 papers cited 1 times, with an average citation rate 447 of 0.06 . However, the 225 full-text articles from AMIA '15 were cited 67 times, of which 1 paper 448 was cited 4 times, 1 paper cited 3 times, 9 papers cited twice, 42 papers cited once, with an 449 average citation rate of 0.3 times per paper, this is 5 times that of CPMI' 15.

450 3. It is a known fact that the big gap in MI conferences between the United States and China 451 is closely associated with their economic strengths and populations as well as their health care 452 systems. 2015 statistics reveal that the United States GDP is 1.78 times that of China (18.04 453 trillion US dollars (OECD 2017a) vs. 10.14 trillion US dollars (Chinese 2014a)), whereas its 454 population is only $23 \%$ of the latter (314 million (OECD 2017c)vs. 1.37 billion (Chinese 455 2014c)). However, the United States' expenditure on health care is $16.9 \%$ of its GDP(OECD 456 2017b), while that of China is $5.95 \%$ (Chinese 2014b). This means that, in the same year, the 457 United States' per capita health expenses amounted to 9451 US dollars (OECD 2017b), whereas 458 Chinese healthcare expenses per capita were only 438 US dollars (Chinese 2014b); the former is 45921.6 times that of the latter. Moreover, the large gap between the Chinese health system and that 460 of the U.S. suggests that, in the U.S., new inventions are quickly applied (Deaton 2015). MI, as a 461 new interdisciplinary field with a naturally broad market prospect, has gathered a good amount 462 of investment funding and support, whereby investors would like to use new technologies to 463 reduce medical expenditures, forcing medical institutions to control costs while also 464 guaranteeing quality healthcare. Thus, it is no surprise that the number of participants of HIMSS 465 (2015) is 10 times that of CHITEC (2015), and AMIA (2015)'s academic achievements are 7.8 466 times those of CPMI (2015). This huge gap implies great room for collaboration between 467 Chinese MI professionals and their U.S. counterparts. For further detailed descriptions, please 468 see Appendix A-3 (Unique Characteristics of Medical Informatics Discipline in China). 


\section{CONCLUSION}

472 In China, medical informatics began in the 1970s and was based on library information 473 science. In contrast, in the U.S., medical informatics is based on computer applications in 474 medicine. At present, a large gap between China and the U.S. exists with respect to research 475 rigor and direction, regional balance in the development of medical informatics disciplines, and 476 the breadth and depth of academic research and industry application. These conclusions are 477 based on our analysis of four Chinese mainstream MI conference proceedings, as well as two 478 major U.S. MI conference proceedings.

479 In addition, the Chinese medical education curriculum initially focused on "medical 480 literature information systems," which was significantly different from the framework of the 481 medical education curriculum in the U.S. and other countries. This difference was demonstrated 482 in CPMI proceedings paper topics.

483 Finally, some relatively large Chinese medical informatics organizations (e.g., CHIMA, 484 SCMI, and CHIA) are not currently IMIA members; CMIA, the only current IMIA member, was 485 previously a secondary institution of the Chinese Institute of Electronics. Consequently, the 486 public status of CMIA, diverging from library information science-based medical informatics, is 487 second only to that of SCMI in the academic community, but compared with CHIMA and CHIA, 488 its business sponsors and attendees are much fewer. Moreover, communication between 489 CHIMA, which focuses on hospital informatics, and CHIA remains a challenge.

490 This study demonstrates an urgent necessity to elevate the medical informatics discipline in 491 China and to expand research fields in order to maintain pace with the development of medical 
492 informatics in the U.S. and other countries. To this end, the authors propose four suggestions: 1)

493 the central Chinese government should establish developmental goals and strategies for the 494 medical informatics discipline; 2) the government should support the integration of medical 495 informatics research with national health informatics; 3) according to international guidelines for 496 medical informatics education prescribed in the latest version of IMIA (Haux \& Murray 2010; 497 Mantas et al. 2010), a framework based on these guidelines and actual conditions in China 498 should be developed to define the professional qualifications of medical informatics personnel; 499 and 4) CHIMA, CHIA, and SCMI should align their organizational efforts with international MI 500 research fields and extant needs to develop medical informatics in China.

501 A special note is that, even though conference analysis has offered interesting insights on 502 the current status of MI in China and the U.S., better measures such as publications and grants 503 will be explored in our next studies. In addition, our current analysis focuses on the development 504 of Medical Informatics in China and comparison to part of that in the United States of America. 505 Our next research plan to include data from Medical Informatics Europe Conferences (MIE) and 506 World Congress on Medical and Health Informatics (MEDINFO), so that the present study can 507 be further extended to the status quo analysis and comparison of China and the European and 508 world medical informatics development.

509 Because of the space limitations of this paper, readers may refer to Appendix A-4 (Several 510 Suggestions for the Development of Medical Informatics Discipline with Chinese 511 Characteristics), if more information is desired. 


\section{REFERENCES:}

515 CHINA NI. 2014a. Beijing. Nature 516:S60-S61. 10.1038/516S60a

516 CHINA NI. 2014b. Nanjing. Nature 516:S66-S66. 10.1038/516S66a

517 Chinese ND. 2014a. Gross domestic product (GDP). Available at

518 http://data.stats.gov.cn/ks.htm?cn=C01\&zb=A0501 (accessed 3.4.2017 (in Chinese)).

519 Chinese ND. 2014b. Health spending. Available at

520 http://data.stats.gov.cn/easyquery.htm?cn=C01 (accessed 3.4.2017(in Chinese)).

521 Chinese ND. 2014c. Population. Available at http://data.stats.gov.cn/ks.htm?cn=C01\&zb=A0501

522 (accessed 3.4.2017 (in Chinese)).

523 Committee CCFA. 2015. China Computer Federation Core Journal and Conference Lists.

524 Available at http://www.cnblogs.com/guolei/p/3576366.html (accessed accessed on

$525 \quad 6.30 .2016$ (in Chinese).

526 Deaton A. 2015. The Great Escape: Health, Wealth, and the Origins of Inequality. Princeton, 527 New Jersey, USA: Princeton University Press.

528 Dong J. 2004. The current situation and future of medical informatics. Chinese Journal of 529 Hopsital Administration 20:232-236. (In Chinese)

530 Fickenscher K. 2013a. President's column: An AMIA update--new directions and new

$531 \quad$ opportunities. J Am Med Inform Assoc 20:208-210. 10.1136/amiajnl-2012-001515

532 Fickenscher KM. 2012a. President's column: Informatics professionals--leading the way? J Am

533 Med Inform Assoc 19:1122. 10.1136/amiajnl-2012-001362

534 Fickenscher KM. 2012b. President's column: two important decisions, one clear direction. J Am

535 Med Inform Assoc 19:918. 10.1136/amiajnl-2012-001225

536 Fickenscher KM. 2013b. President's column: AMIA -- expanding and extending our reach. J Am 537 Med Inform Assoc 20:401-402. 10.1136/amiajnl-2013-001649

538 Fickenscher KM. 2013c. President's column: interoperability--the 30\% solution: from dialog and 539 rhetoric to reality. J Am Med Inform Assoc 20:593-594. 10.1136/amiajnl-2013-001768

540 Fickenscher KM. 2013d. President's column: population health--the ultimate application of 541 informatics! J Am Med Inform Assoc 20:803-804. 10.1136/amiajnl-2013-001976

542 Haux R. 2010. Medical informatics: past, present, future. Int J Med Inform 79:599-610.

$543 \quad 10.1016 /$ j.ijmedinf.2010.06.003 
544 Haux R, and Murray PJ. 2010. On IMIA's International Activities in Health and Biomedical 545 Informatics Education. Methods Inf Med 49:305-309. 10.3414/me09-02-0019

$546 \mathrm{Hu}$ J, Xin Y, and Q M. 2016. Ten Features of Health Informatization Development during

547

548

549

550

551

552

553

554

555

556

557

558

559

560

561

562

563

564

565

566

567

568

569

570

571

572 the12th Five-Year-Plan Period. CHINESE JOURNAL OF HEALTH INFORMATICS AND MANAGEMENT 13:13-17. (In Chinese)

Kulikowski CA. 2007. IMIA: coalescing medical informatics worldwide for 40 years. Yearb Med Inform:176-185.

Kulikowski CA. 2014. The 50(th) Anniversary IMIA History of Medical Informatics Project. Acta Inform Med 22:68-70. 10.5455/aim.2014.22.68-70

Kulikowski CA, Shortliffe EH, Currie LM, Elkin PL, Hunter LE, Johnson TR, Kalet IJ, Lenert LA, Musen MA, Ozbolt JG, Smith JW, Tarczy-Hornoch PZ, and Williamson JJ. 2012. AMIA Board white paper: definition of biomedical informatics and specification of core competencies for graduate education in the discipline. J Am Med Inform Assoc 19:931938. 10.1136/amiajnl-2012-001053

Lei J, Meng Q, Li Y, Liang M, and Zheng K. 2016. The evolution of medical informatics in China: A retrospective study and lessons learned. Int J Med Inform 92:8-14. 10.1016/j.jjmedinf.2016.04.011

Li H. 2015. The Analysis of the Essay from 2015 Chinese Health Information Network Conference. China Digital Medicine 15:1-1. (In Chinese)

LI H, and LIU H. 2014. Review of medical informatics education in the past 10 years and suggestions for its future development. Chin J Med Libr Inf Sci 23:1-6. (In Chinese)

Luo J. 2014. China Medical Informationization Industry Indepth Research and Investment Strategy Planning Report, 2015-2020. Forward Co.,Ltd. (In Chinese)

M.J.Sehuemie, J.L.Talmon, and P.W.Moorlna. 2009. Mapping the Domain of Medical Informatics Methods Inf Med 48:76-83.

Mantas J, Ammenwerth E, Demiris G, Hasman A, Haux R, Hersh W, Hovenga E, Lun KC, Marin H, Martin-Sanchez F, and Wright G. 2010. Recommendations of the International Medical Informatics Association (IMIA) on Education in Biomedical and Health Informatics. First Revision. Methods Inf Med 49:105-120. 10.3414/me5119 
573 Maojo V, Garcia-Remesal M, Bielza C, Crespo J, Perez-Rey D, and Kulikowski C. 2012.

574 Biomedical informatics publications: a global perspective: part I: conferences. Methods

$575 \quad$ Inf Med 51:82-90. 10.3414/me11-01-0060

576 Middleton B. 2014. President's column: AMIA's policy priorities for 2014. J Am Med Inform

577 Assoc 21:574. 10.1136/amiajnl-2014-002809

578 Moher D, Liberati A, Tetzlaff J, and Altman DG. 2009. Reprint--preferred reporting items for

579 systematic reviews and meta-analyses: the PRISMA statement. Physical Therapy 89:873$580 \quad 880$.

581 OECD. 2017a. Gross domestic product (GDP) (indicator). Available at

582 https://data.oecd.org/gdp/gross-domestic-product-gdp.htm (accessed 3.4.2017).

583 OECD. 2017b. Health spending (indicator). Available at https://data.oecd.org/healthres/health$584 \quad$ spending.htm (accessed 3.4.2017).

585 OECD. 2017c. Population (indicator). Available at https://data.oecd.org/pop/population.htm $586 \quad$ (accessed 3.4.2017).

587 Qun M. 2011. Introduction to guiding opinions and development planning of health 588 informatization construction in China (2011-2015). Xiameng: IT and Statistics Center, 589 590

591

592

593

594

595

596

597

598

599

600

601

602

603 National Health and Family Planning Commission of the People's Republic of China. (In Chinese)

Ravvaz K, Kuziemsky C, Koppel R, Kaplan B, Adams SA, and Adams MB. 2015. AMIA members' "vital signs": what the HIT implementation listserv says about goals for AMIA and for medical informatics. AMIA Annu Symp Proc 2015:1067-1075.

Shi YK, and Zheng SW. 2008. Strategic supporting role of a regional state-level hospital during medical rescue after Wenchuan earthquake. J Evid Based Med 1:15-19. 10.1111/j.17565391.2008.00002.x

Shortliffe EH. 2011a. AMIA president's column: AMIA and HIT policy activities. $J$ Am Med Inform Assoc 18:537-538. 10.1136/amiajnl-2011-000353

Shortliffe EH. 2011b. President's column: subspecialty certification in clinical informatics. $J \mathrm{Am}$ Med Inform Assoc 18:890-891. 10.1136/amiajnl-2011-000582

Ya-min L, Yan L, and Xiao-tao L. 2011. Papers contributed to 1-15 national medical information academic conferences of Chinese Medical Association. Chin J Med Libr Inf Sci 20:1-5. (In Chinese) 
604 Yajie Z, Ying X, Yan Z, Huiying H, and Qun M. 2015. The Analysis of the Essay from 2015 605 Chinese Health Information Technology Exchange Conference. Chinese JoumaI of $606 \quad$ Heallh Informatics and Management 12:654-657. (In Chinese)

607 Yajie Z, Ying X, Yuefeng L, Huiying H, and Qun M. 2014. The Analysis of the Essay from 2014

608 Chinese Health Information Technology Exchange Conference. CHINESE JOURNAL

609 OF HEALTH INFORMATICS AND MANAGEMENT 11:640-643. (In Chinese)

610 
612

613

614 TABLES

615 Table 1. Basic information on the CMIAAS, CHINC, CHITEC, and CPMI conferences.

616 CMIAAS, only 12 conferences have been held since 1981-2015; CPMI, 24 conferences have

617 been held since 1993-2016; CHITEC, only 13 conferences have been held since 2004-2016;

618 CHINC, 20 conferences have been held since 1997-2016.

619

620 Table 2. Summary of the CMIAAS, 2015; CHINC, 2015; CHITEC, 2015; CPMI, 2015; AMIA, 621 2015; and HIMSS, 2015 conferences.

622 


\section{FIGURES}

625

626 Figure 1. Conference proceedings of the CMIAAS (2008-2015), CHINC (2008, 2012, 2014,

627 2015), CHITEC (2008, 2011, 2013-2015), and CPMI (2008-2012, 2014, 2015).

628

629 Figure 2. The number of CMIAAS (2008-2015), CHINC (2008-2016), CHITEC (2008-2016), 630 and CPMI (2008-2016) conference attendees.

631

632 Figure 3. Author affiliations at four mainstream Chinese medical informatics conferences

633 (CMIAAS, CHINC, CHITEC, and CPMI).

634

635 Figure 4. Geographic distribution of authors among the CMIAAS, CHINC, CHITEC, and CPMI 636 conferences (the top three provinces and/or municipalities are listed).

637

638 Figure 5. Distribution of topics among the CMIAAS, CHINC, CHITEC, and CPMI conference 639 proceedings.

640

641 Figure 6. Comparison of major characteristics of MI conferences (academic) in the U.S. and 642 China, 2015.

643

644 Figure 7. Comparison of major characteristics of MI conferences (industry) in the U.S. and 645 China, 2015. 


\section{Table $\mathbf{1}$ (on next page)}

Basic information on the CMIAAS, CHINC, CHITEC, and CPMI conferences.

CMIAAS, only 12 conferences have been held since 1981-2015; CPMI, 24 conferences have been held since 1993-2016; CHITEC, only 13 conferences have been held since 2004-2016; CHINC, 20 conferences have been held since 1997-2016. 
1

\begin{tabular}{|c|c|c|c|c|c|c|c|}
\hline & Organizer & Inception & Schedule & $\begin{array}{c}\text { Number of } \\
\text { Conferences Held }\end{array}$ & Conference Duration & Type & $\begin{array}{c}\text { Scale of Last } \\
\text { Conference (number } \\
\text { of attendees) } \\
\end{array}$ \\
\hline CMIAAS & $\begin{array}{c}\text { China Medical } \\
\text { Informatics } \\
\text { Association }\end{array}$ & 1981 & $\begin{array}{c}\text { Every } 3 \\
\text { years }\end{array}$ & 12 & 1 day & $\begin{array}{l}\text { Academic } \\
\text { conference }\end{array}$ & $200+($ CMIAAS 2015) \\
\hline CPMI & $\begin{array}{c}\text { Medical } \\
\text { Informatics Branch, } \\
\text { Chinese Medical } \\
\text { Association }\end{array}$ & 1993 & Annual & 24 & 1 day & $\begin{array}{l}\text { Academic } \\
\text { conference }\end{array}$ & $500+($ CPMI 2016) \\
\hline CHITEC & $\begin{array}{l}\text { China Institutes of } \\
\text { Health Information }\end{array}$ & 2004 & Annual & 13 & 2 days & $\begin{array}{c}\text { Industry } \\
\text { conference }\end{array}$ & $5000+($ CHITEC 2016) \\
\hline CHINC & $\begin{array}{l}\text { Committee on } \\
\text { Information } \\
\text { Management, } \\
\text { Chinese Hospital } \\
\text { Association }\end{array}$ & 1997 & Annual & 20 & 3 days & $\begin{array}{c}\text { Industry } \\
\text { conference }\end{array}$ & $3500+($ CHINC 2016) \\
\hline
\end{tabular}

2 Table 1. Basic information on the CMIAAS, CHINC, CHITEC, and CPMI conferences. CMIAAS, only 12 conferences have been

3 held since 1981-2015; CPMI, 24 conferences have been held since 1993-2016; CHITEC, only 13 conferences have been held since

4 2004-2016; CHINC, 20 conferences have been held since 1997-2016. 


\section{Table 2 (on next page)}

Summary of the CMIAAS, 2015; CHINC, 2015; CHITEC, 2015; CPMI, 2015; AMIA, 2015; and HIMSS, 2015 conferences. 


\begin{tabular}{|c|c|c|c|c|c|c|c|c|c|c|}
\hline $\begin{array}{c}\text { Conference } \\
\text { Name }\end{array}$ & Organizer & Inception & Schedule & $\begin{array}{c}\text { Meeting } \\
\text { Duration }\end{array}$ & $\begin{array}{l}\text { Number } \\
\text { of } \\
\text { Attendees }\end{array}$ & $\begin{array}{l}\text { Composition } \\
\text { of Attendees }\end{array}$ & $\begin{array}{c}\text { Academic } \\
\text { Achievement }\end{array}$ & $\begin{array}{c}\text { Paper } \\
\text { Review } \\
\text { Mechanism }\end{array}$ & $\begin{array}{c}\text { Number of } \\
\text { Participating } \\
\text { Companies }\end{array}$ & $\begin{array}{c}\text { Fields } \\
\text { Covered }\end{array}$ \\
\hline $\begin{array}{l}\text { CMIAAS } \\
2015\end{array}$ & $\begin{array}{l}\text { China } \\
\text { Medical } \\
\text { Informatics } \\
\text { Association }\end{array}$ & 1981 & $\begin{array}{l}\text { Every } 3 \\
\text { years }\end{array}$ & 1 day & $200+$ & $\begin{array}{l}\text { Medical } \\
\text { institutions, } \\
\text { universities, } \\
\text { research } \\
\text { institutes }\end{array}$ & $\begin{array}{l}\text { Four forums, } 71 \\
\text { conference } \\
\text { papers }\end{array}$ & $\begin{array}{l}\text { Format } \\
\text { review only }\end{array}$ & 5 & $\begin{array}{l}\mathrm{B}, \mathrm{D}, \mathrm{I}, \mathrm{F}, \\
\mathrm{P}, \mathrm{T}\end{array}$ \\
\hline CPMI 2015 & $\begin{array}{l}\text { Medical } \\
\text { Informatics } \\
\text { Branch, } \\
\text { Chinese } \\
\text { Medical } \\
\text { Association }\end{array}$ & 1993 & Annual & 1 day & $300+$ & $\begin{array}{l}\text { Medical } \\
\text { institutions, } \\
\text { research } \\
\text { institutes, } \\
\text { universities }\end{array}$ & $\begin{array}{l}\text { Four forums, } \\
248 \text { conference } \\
\text { papers, } \\
\text { including } 13 \\
\text { papers } \\
\text { presented at the } \\
\text { general } \\
\text { conference and } \\
48 \text { papers at } \\
\text { forums }\end{array}$ & $\begin{array}{l}\text { Format } \\
\text { review only }\end{array}$ & 13 & $\begin{array}{l}\mathrm{L}, \mathrm{D}, \mathrm{B}, \mathrm{F}, \\
\mathrm{P}\end{array}$ \\
\hline $\begin{array}{l}\text { AMIA } 2015 \\
\text { annual } \\
\text { symposium }\end{array}$ & $\begin{array}{l}\text { American } \\
\text { Medical } \\
\text { Informatics } \\
\text { Association }\end{array}$ & 1977 & Annual & 4 days & $2300+$ & $\begin{array}{l}\text { Medical } \\
\text { institutions, } \\
\text { universities, } \\
\text { research } \\
\text { institutions, } \\
\text { companies }\end{array}$ & $\begin{array}{l}\text { Ten forums, } 14 \\
\text { continuing } \\
\text { education } \\
\text { classes, and } 114 \\
\text { lectures; } 156 \\
\text { full-text papers, } \\
80 \text { abstracts, } 36 \\
\text { exchange } \\
\text { articles, } 1109\end{array}$ & $\begin{array}{l}\text { Rigorous } \\
\text { peer review } \\
\text { mechanism }\end{array}$ & 50 & $\begin{array}{l}\text { A, B, C, D, } \\
\text { E, F, G, H, } \\
\text { I, J, K, L, } \\
\text { M, N, O, P, } \\
\text { Q, R, S, T }\end{array}$ \\
\hline
\end{tabular}




\begin{tabular}{|c|c|c|c|c|c|c|c|c|c|c|}
\hline & & & & & & & $\begin{array}{l}\text { posters, } 12 \\
\text { system } \\
\text { presentations, } 7 \\
\text { contests of } \\
\text { student-led } \\
\text { project design. }\end{array}$ & & & \\
\hline $\begin{array}{l}\text { AMIA } 2015 \\
\text { joint } \\
\text { summits }\end{array}$ & & 2008 & Annual & 4 days & $1400+$ & & $\begin{array}{l}\text { Sixteen } \\
\text { forums, } 6 \\
\text { continuing } \\
\text { education } \\
\text { classes, } 136 \\
\text { lectures; } 66 \\
\text { full-text } \\
\text { papers, } 158 \\
\text { posters }\end{array}$ & & 15 & \\
\hline $\begin{array}{l}\text { CHITEC } \\
2015\end{array}$ & $\begin{array}{l}\text { China } \\
\text { Institutes of } \\
\text { Health } \\
\text { Information }\end{array}$ & 2004 & Annual & 2 days & $3300+$ & $\begin{array}{l}\text { Medical } \\
\text { institutions, } \\
\text { research } \\
\text { institutes, } \\
\text { government } \\
\text { authorities, } \\
\text { enterprises, } \\
\text { some } \\
\text { universities }\end{array}$ & $\begin{array}{l}\text { Ten forums, } 87 \\
\text { continuing } \\
\text { education } \\
\text { lectures; } 667 \\
\text { conference } \\
\text { papers, of } \\
\text { which } 37 \text { were } \\
\text { nominated as } \\
\text { "outstanding } \\
\text { papers" }\end{array}$ & $\begin{array}{l}\text { Format } \\
\text { review only }\end{array}$ & $100+$ & $\begin{array}{l}\mathrm{M}, \mathrm{N}, \mathrm{K}, \mathrm{C}, \\
\mathrm{D}, \mathrm{I}, \mathrm{F}, \mathrm{H}, \\
\mathrm{Q}, \mathrm{T}\end{array}$ \\
\hline
\end{tabular}




\begin{tabular}{|c|c|c|c|c|c|c|c|c|c|c|}
\hline CHINC 2015 & $\begin{array}{l}\text { Committee } \\
\text { on } \\
\text { Information } \\
\text { Management, } \\
\text { Chinese } \\
\text { Hospital } \\
\text { Association }\end{array}$ & 1997 & Annual & 3 days & 3500 & $\begin{array}{l}\text { Medical } \\
\text { institutions, } \\
\text { enterprises, } \\
\text { some } \\
\text { universities } \\
\text { and research } \\
\text { institutes }\end{array}$ & $\begin{array}{l}\text { Seven forums, } \\
99 \text { continuing } \\
\text { education } \\
\text { lectures; } 853 \\
\text { conference } \\
\text { papers, of } \\
\text { which } 71 \text { were } \\
\text { nominated as } \\
\text { "outstanding } \\
\text { papers" }\end{array}$ & $\begin{array}{l}\text { Format } \\
\text { review only }\end{array}$ & $150+$ & $\begin{array}{l}\mathrm{B}, \mathrm{D}, \mathrm{I}, \mathrm{F}, \\
\mathrm{P}, \mathrm{T}\end{array}$ \\
\hline HIMSS 2015 & $\begin{array}{l}\text { Healthcare } \\
\text { Information } \\
\text { and } \\
\text { Management } \\
\text { Systems } \\
\text { Society of } \\
\text { the US }\end{array}$ & 1962 & Annual & 4 days & $38,000+$ & $\begin{array}{l}\text { Companies, } \\
\text { medical } \\
\text { institutions, } \\
\text { research } \\
\text { institutions }\end{array}$ & $\begin{array}{l}\text { More than } 250 \\
\text { forums and } \\
\text { presentations, } \\
\text { more than } 300 \\
\text { continuing } \\
\text { education } \\
\text { lectures, one- } \\
\text { day pre- } \\
\text { conference } \\
\text { seminar }\end{array}$ & $\begin{array}{l}\text { Presenters } \\
\text { required to } \\
\text { submit } \\
\text { abstracts } \\
\text { and PPT } \\
\text { for peer } \\
\text { review }\end{array}$ & $\begin{array}{l}1200+\text {, with } \\
\text { review } \\
\text { performed } \\
\text { between } 12 \\
\text { regions }\end{array}$ & $\begin{array}{l}\mathrm{L}, \mathrm{D}, \mathrm{B}, \mathrm{F}, \\
\mathrm{P}\end{array}$ \\
\hline
\end{tabular}

2 Table 2. Summary of the CMIAAS, 2015; CHINC, 2015; CHITEC, 2015; CPMI, 2015; AMIA, 2015; and HIMSS, 2015 conferences.

3 Notes:

4 A: consumer health informatics; B: clinical information management; C: decision support system; D: electronic medical records; E:

5 medical language processing; F: nursing informatics; G: achievement evaluation; H: public health informatics: I: information

6 retrieval; J: medical cognitive science; $\mathbf{K}$ : clinical project management; L: computer-based training; $\mathbf{M}$ : coding, classification and 
7 terminology; $\mathbf{N}$ : clinical guidelines for computerization; $\mathbf{O}$ : image, robotics, virtual medical treatment; $\mathbf{P}$ : signal processing; $\mathbf{Q}$ :

8 standards, social and legal issues; $\mathbf{R}$ : dental informatics; $\mathbf{S}$ : artificial intelligence; T: telemedicine. 
Figure 1

Conference proceedings of the CMIAAS (2008-2015), CHINC (2008, 2012, 2014, 2015), CHITEC (2008, 2011, 2013-2015), and CPMI (2008-2012, 2014, 2015).

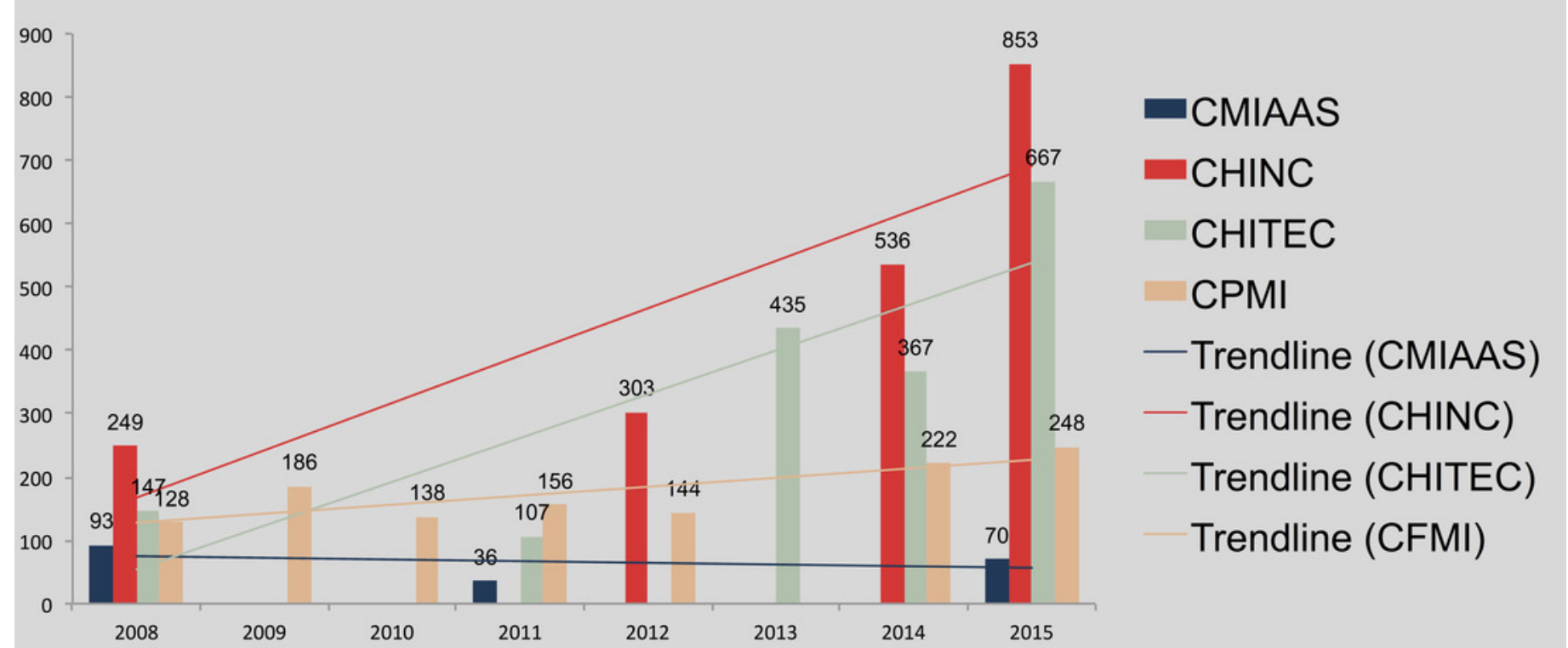


Figure 2

The number of CMIAAS (2008-2015), CHINC (2008-2016), CHITEC (2008-2016), and CPMI (2008-2016) conference attendees.

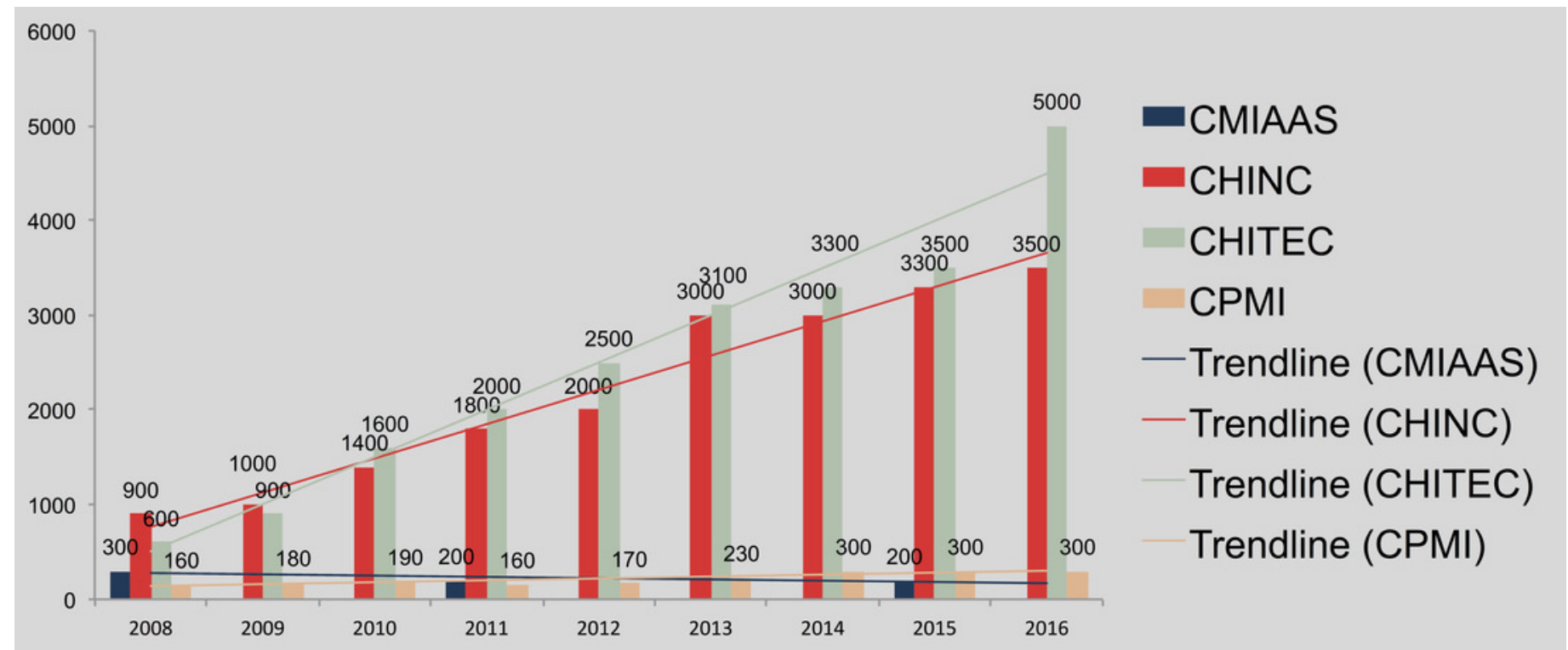




\section{Figure 3}

Author affiliations at four mainstream Chinese medical informatics conferences (CMIAAS, CHINC, CHITEC, and CPMI).

CMIAAS (2008-2015) (A)

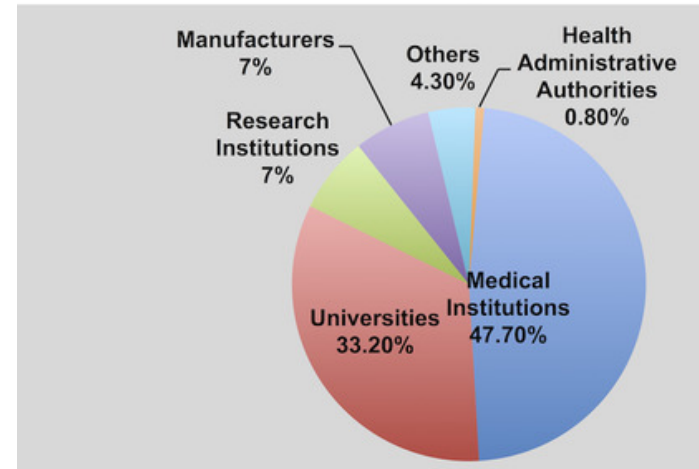

CHITEC （2008, 2011, 2013-2015）

(C)

CHINC （2008, 2012, 2014-2015）

(D)

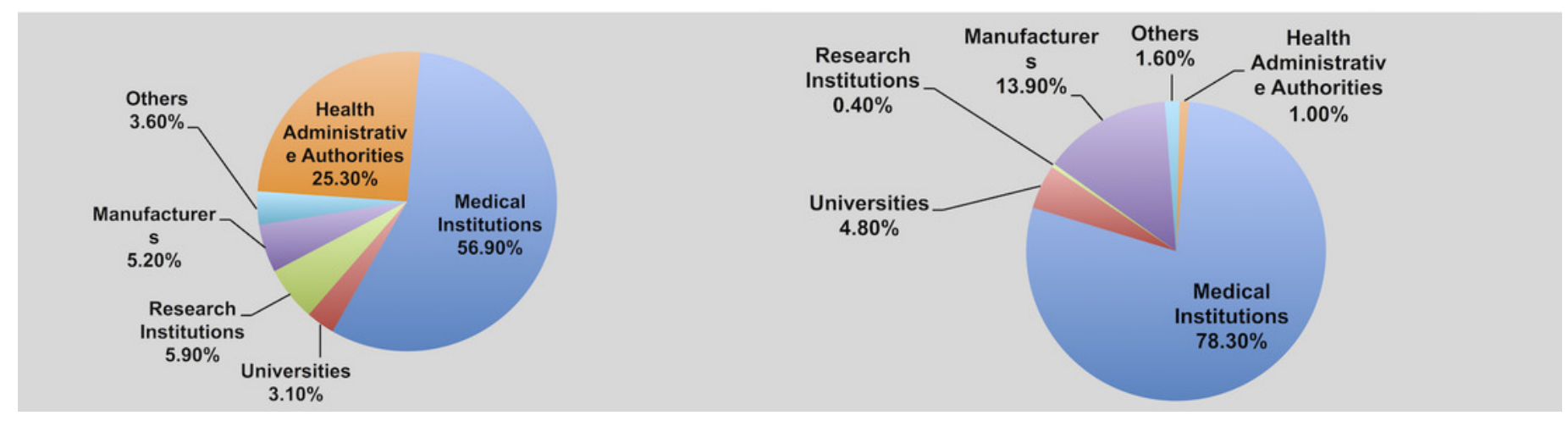


Figure 4

Geographic distribution of authors among the CMIAAS, CHINC, CHITEC, and CPMI conferences (the top three provinces and/or municipalities are listed).

CMIAAS (2008-2015) (A)

CPMI (2008-2012, 2014-2015) (B)

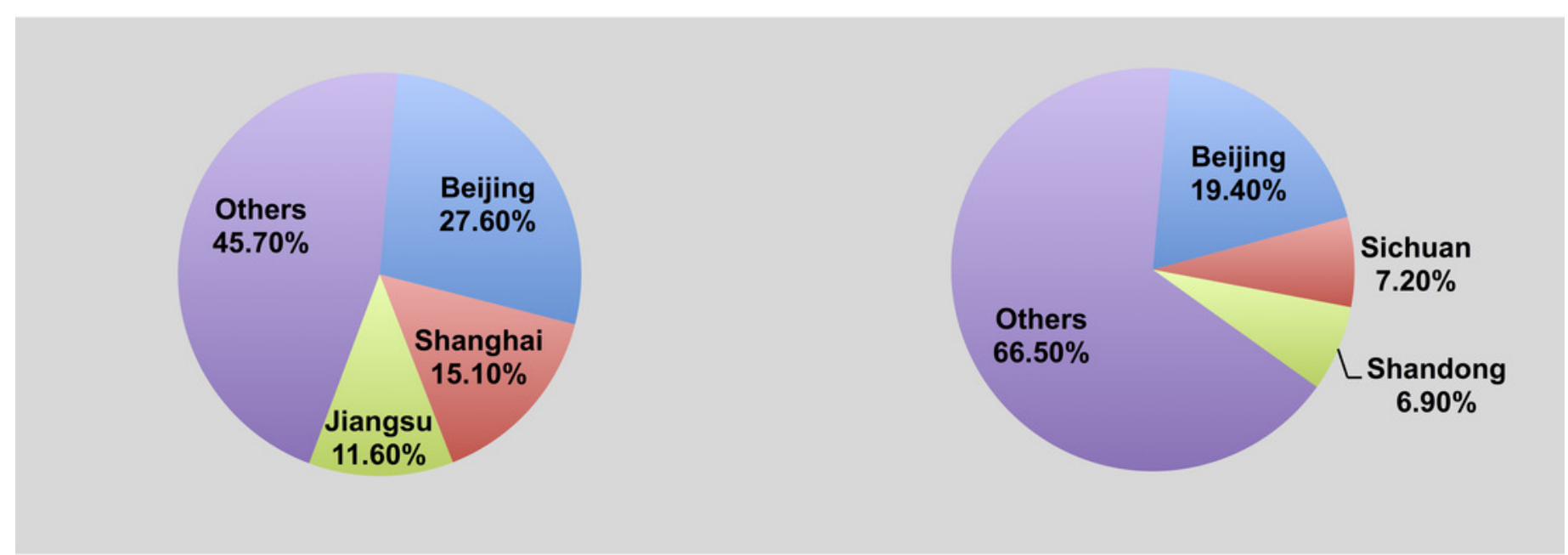

CHITEC $(2008,2011,2013-2015)(C) \quad$ CHINC $(2008,2012,2014-2015)$ (D)
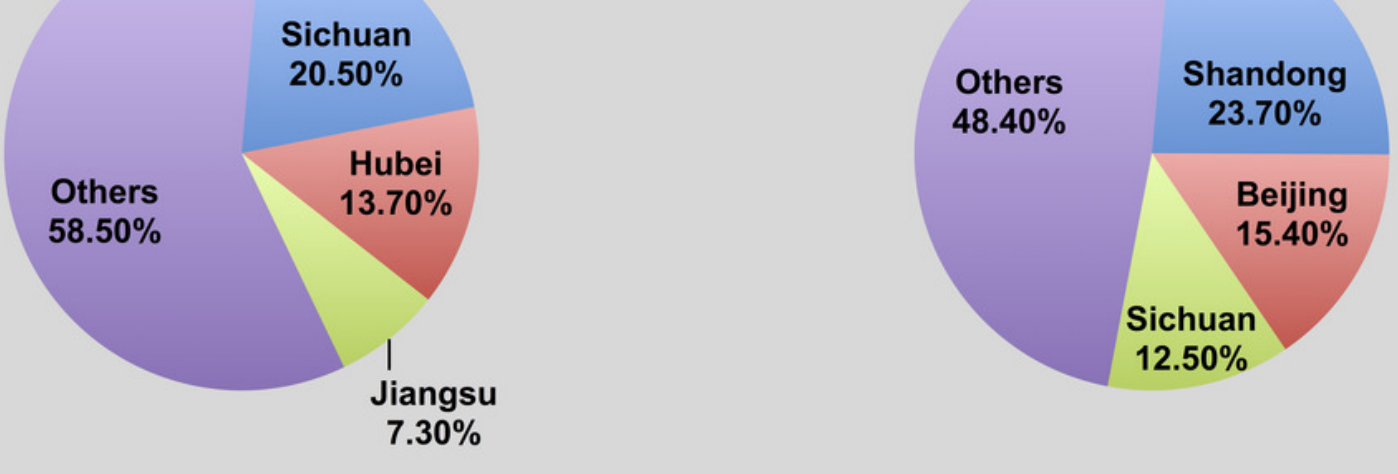


\section{Figure 5}

\section{Distribution of topics among the CMIAAS, CHINC, CHITEC, and CPMI conference proceedings.}

CPMI （2008-2012, 2014-2015）

(B)

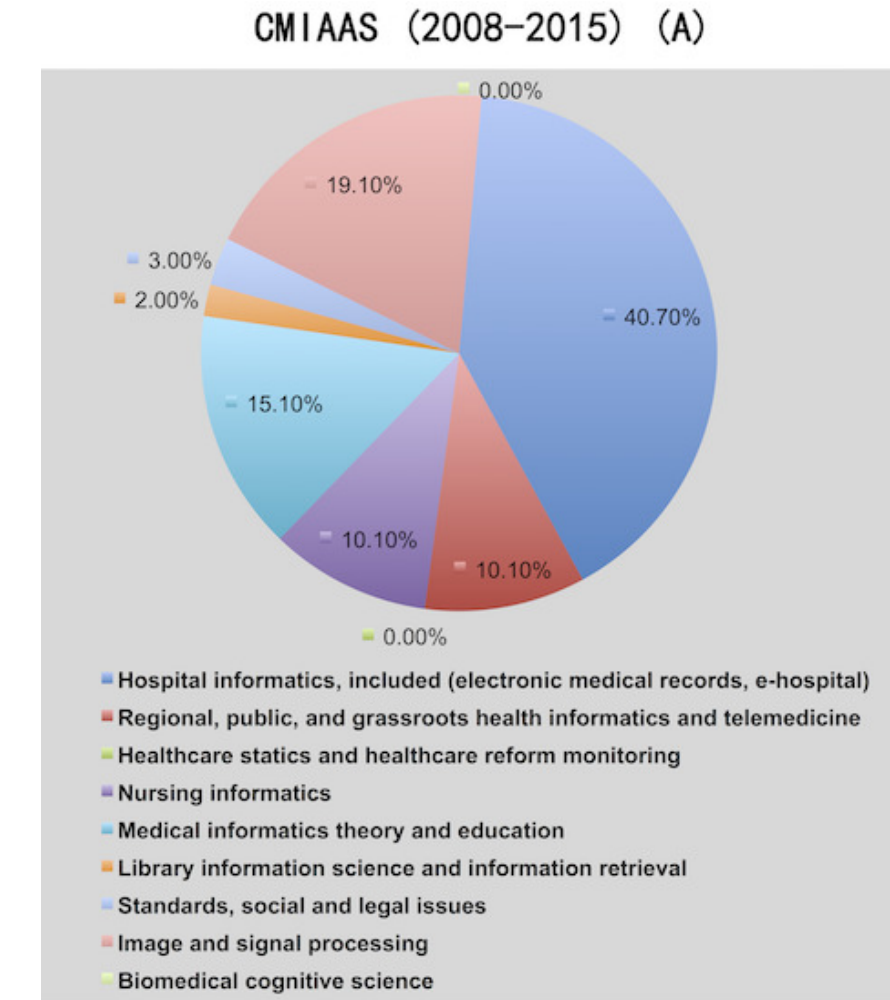

CHITEC （2008, 2011, 2013-2015）

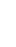

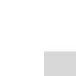

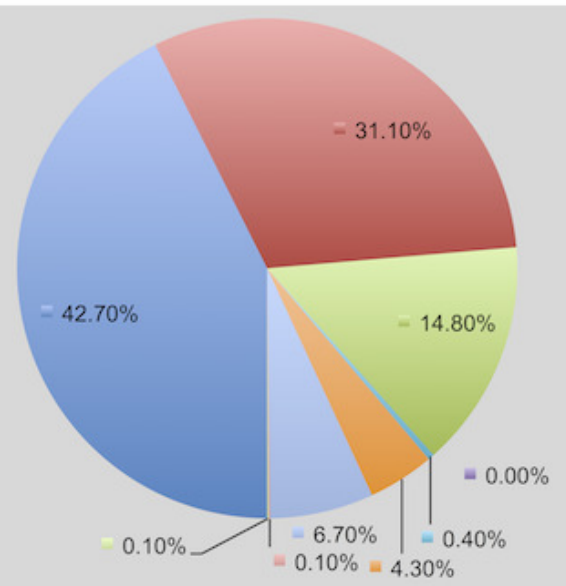

- Hospital informatics, included (electronic medical records, e-hospital)

= Regional, public, and grassroots health informatics and telemedicine

- Healthcare statics and healthcare reform monitoring

- Nursing informatics

- Medical informatics theory and education

- Library information science and information retrieval

Standards, social and legal issues

- Image and signal processing

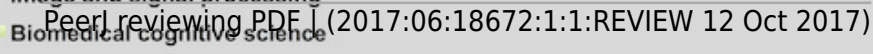

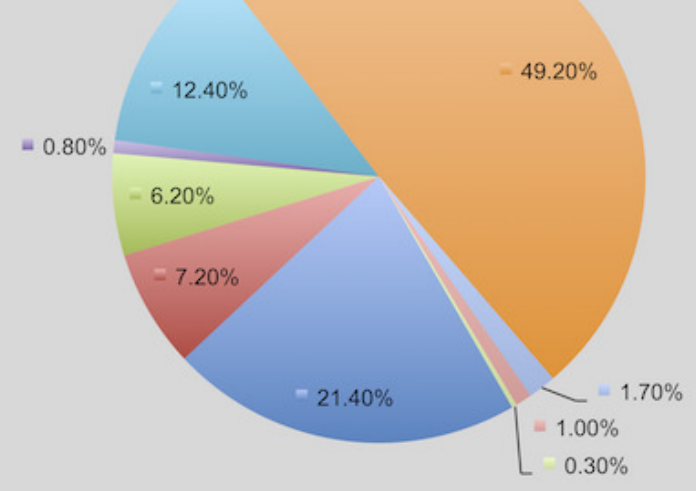

- Hospital informatics, included (electronic medical records, e-hospital)

- Regional, public, and grassroots health informatics and telemedicine

- Healthcare statics and healthcare reform monitoring

- Nursing informatics

Medical informatics theory and education

Library information science and information retrieval

Standards, social and legal issues

Image and signal processing

Biomedical cognitive science

(D)

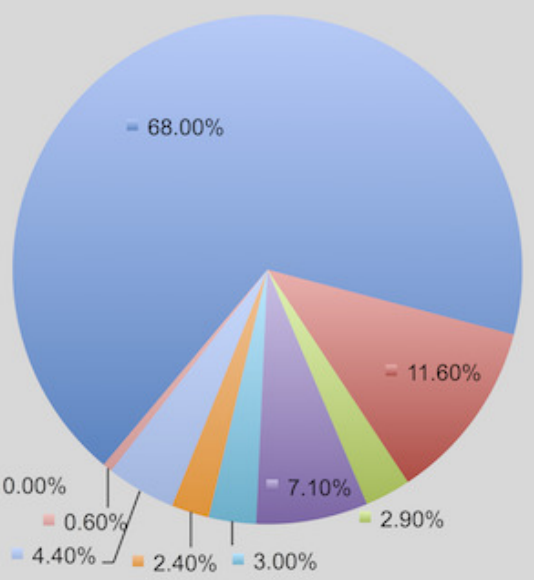

- Hospital informatics, included (electronic medical records, e-hospital)

- Regional, public, and grassroots health informatics and telemedicine

- Healthcare statics and healthcare reform monitoring

- Nursing informatics

- Medical informatics theory and education

- Library information science and information retrieval

Standards, social and legal issues

Image and signal processing

Biomedical cognitive science 
Figure 6

Comparison of major characteristics of MI conferences (academic) in the U.S. and China, 2015.

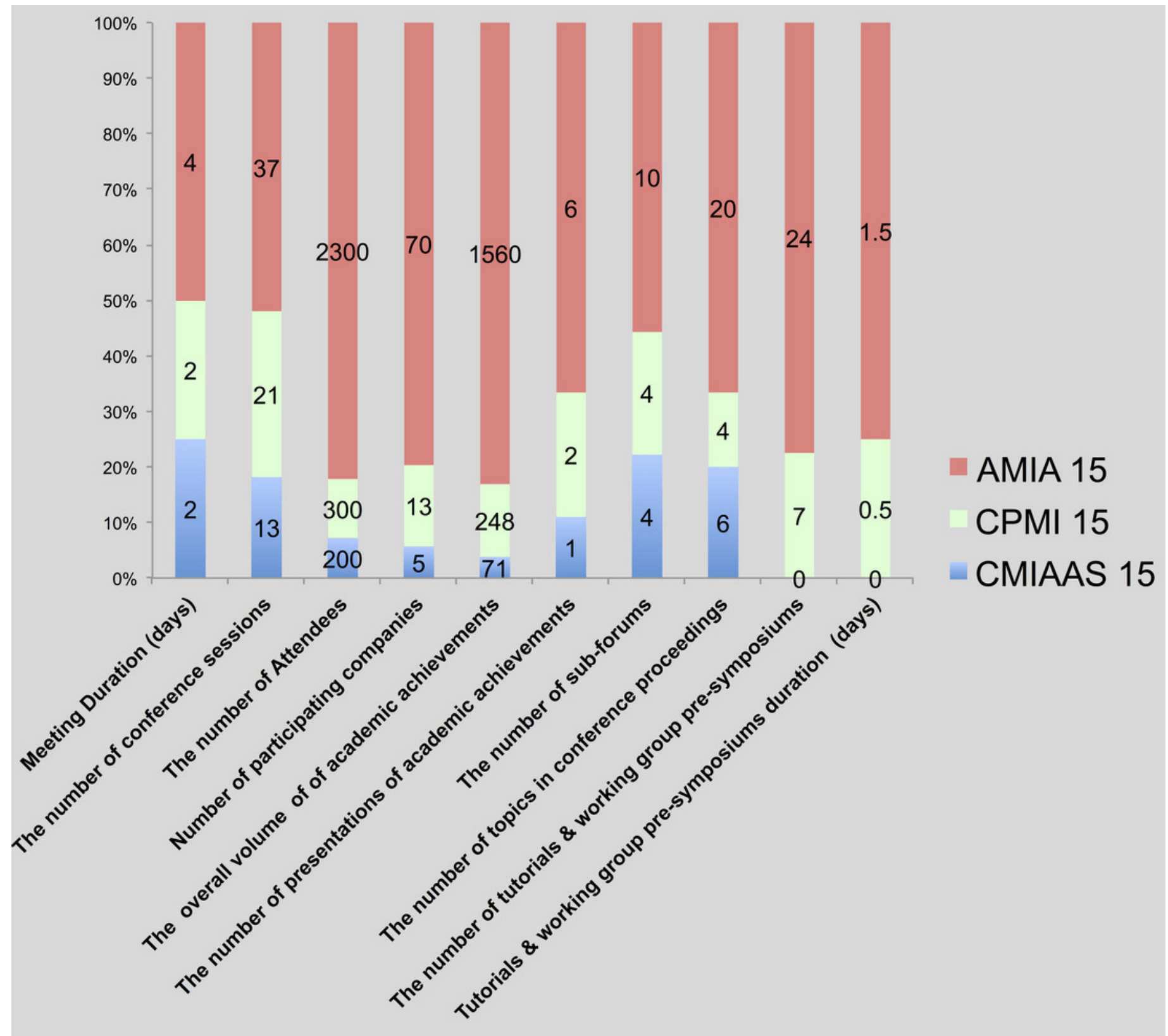


Figure 7

Comparison of major characteristics of $\mathrm{Ml}$ conferences (industry) in the U.S. and China, 2015.

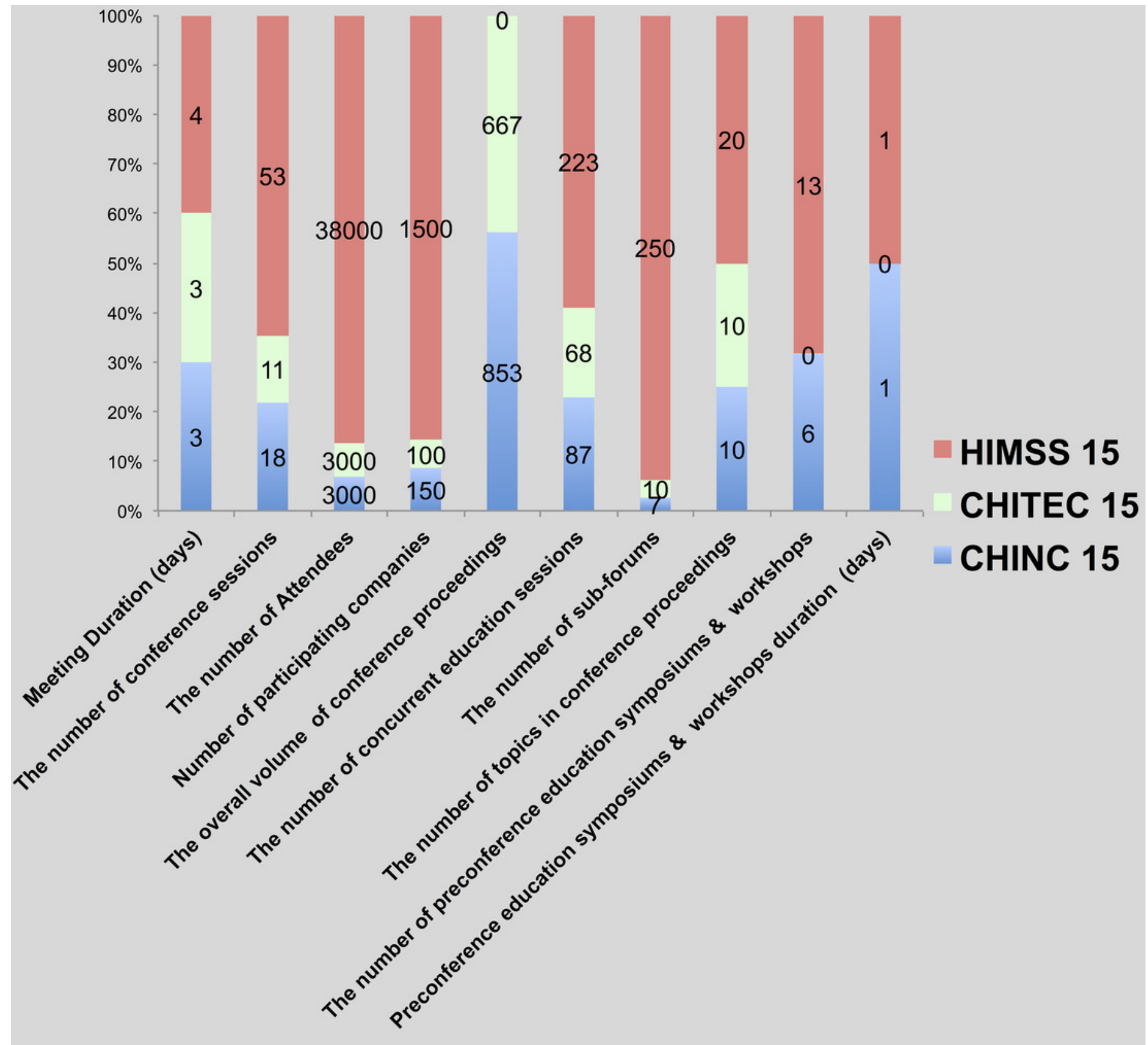

